\title{
Alpha-glucosidase inhibitors in the early treatment of type 2 diabetes
}

\author{
Floris Alexander van de Laar \\ Radboud University Nijmegen Medical \\ Centre, Department of General \\ Practice, Nijmegen, The Netherlands
}

\begin{abstract}
Alpha-glucosidase inhibitors (AGIs) are drugs that inhibit the absorption of carbohydrates from the gut and may be used in the treatment of patients with type 2 diabetes or impaired glucose tolerance. There is currently no evidence that AGIs are beneficial to prevent or delay mortality or micro- or macrovascular complications in type 2 diabetes. Its beneficial effects on glycated hemoglobin are comparable to metformin or thiazolidinediones, and probably slightly inferior to sulphonylurea. In view of the total body of evidence metformin seems to be superior to AGIs. More long-term studies are needed to study the effects of AGIs compared to other drugs. For patient with impaired glucose tolerance AGIs may prevent, delay or mask the occurrence of type 2 diabetes. A possible beneficial effect on cardiovascular events should be confirmed in new studies.
\end{abstract}

Keywords: alpha-glucosidase inhibitors, type 2 diabetes mellitus, impaired glucose tolerance

\section{Introduction}

Type 2 diabetes (DM2) and associated cardiovascular diseases and cancer are an increasing problem around the globe, especially in the developed world (Beaglehole and Yach 2003). Currently, in the Netherlands the prevalence of DM2 is approximately $3.5 \%$ and this number is expected to increase by at least $32 \%$ in the next decades. This is due to the changing demographic characteristics (more elderly people), increasing problem of overweight and the improved and early detection of patients with DM2 (Baan and Poos 2007).

The diagnosis of DM2 is not clear-cut, but merely the result of an arbitrarily chosen point somewhere between the absence of insulin resistance and normal insulin secretion, and advanced peripheral insulin resistance and absence of insulin production. Therefore, the optimal moment to start treatment is not unequivocal. Specific criteria have been defined for those people who have raised post-prandial and/or fasting blood glucose, but who do not meet the criteria for DM2. This condition is referred to as 'impaired glucose tolerance' (IGT) when post-prandial blood glucose levels are elevated, and 'impaired fasting blood glucose' (IFBG) in case of elevated fasting blood glucose (criteria: Table 1).

In this paper, the current evidence is reviewed for the use of AGIs as initial treatment for patients with DM2, or as treatment for patients with IGT and/or IFBG.

\section{Alpha-glucosidase inhibitors for treatment of type $\mathbf{2}$ diabetes mellitus}

Diet and exercise is the first step in the treatment of DM2. But if these measures alone fail to sufficiently control blood glucose levels, starting oral drug therapy is recommended (Rutten et al 2006). To date, 6 classes of oral antihyperglycemic drugs are available: biguanides (metformin), sulphonylurea (eg, tolbutamide), glinidines (eg, repaglinide), thiazolidinediones (eg, pioglitazone), dipeptidyl peptidase IV inhibitors (eg, sitagliptin) and alpha-glucosidase inhibitors (AGIs; eg, acarbose) (Nathan 2007). 
Table I Current definitions for diabetes mellitus, impaired glucose tolerance and impaired fasting blood glucose

\begin{tabular}{|c|c|c|c|}
\hline & WHO 2006 & ADA 2007 & Rutten et al 2006 \\
\hline Diabetes mellitus & $\begin{array}{l}\mathrm{FPG} \geq 7.0 \\
\text { or } \\
2 \mathrm{HPG} \geq \mathrm{II} . \mathrm{I}\end{array}$ & $\begin{array}{l}\text { Symptoms of diabetes } \\
\text { plus CPG } \geq 11.1 \\
\text { or } \\
\text { FPG } \geq 7.0 \\
\text { or } \\
2 \mathrm{HPG} \geq 11 . \mathrm{I}^{\mathrm{b}}\end{array}$ & $\begin{array}{l}\text { Symptoms of diabetes } \\
\text { plus CPG } \geq 11.1 \\
\text { or } \\
\text { FPG } \geq 7.0 \text { on two } \\
\text { occasions }\end{array}$ \\
\hline $\begin{array}{l}\text { Impaired glucose } \\
\text { tolerance }\end{array}$ & $\begin{array}{l}\text { FPG }<7.0 \\
\text { and } \\
2 \text { HPG 7.8-11.0 }\end{array}$ & $2 \mathrm{HPG} 7.8-11.0^{\circ}$ & No definition \\
\hline $\begin{array}{l}\text { Impaired fasting } \\
\text { blood glucose }\end{array}$ & $\begin{array}{l}\text { FPG 6.I-6.9 } \\
\text { and (if measured) } \\
2 \mathrm{HPG}<7.8\end{array}$ & FPG 5.6-6.9c & FPG $>6.1$ and $<6.9^{c}$ \\
\hline
\end{tabular}

Notes: All values are venous plasma glucose concentrations (mmol/L).

2HPG, 2 hours plasma glucose, glucose concentration 2 hours after ingestion of $75 \mathrm{~g}$ glucose; CPG, casual plasma glucose, casual is defined as any time of day without regard to time since last meal; FPG, fasting plasma glucose, fasting is defined as no caloric intake for $\geq 8$ hours.

aThe classic symptoms of diabetes include polyuria, polydipsia, and unexplained weight loss.

'These criteria should be confirmed by repeat testing 'in the absence of unequivocal hyperglycemia'.

'Excluding patients fulfilling the criteria for type 2 diabetes.

AGIs reversibly inhibit a number of alpha-glucosidase enzymes (eg, maltase), consequently delaying the absorption of sugars from the gut (Campbell et al 1996). In a recent study among healthy subjects it was suggested that the therapeutic effects of AGIs are not only based on a delayed digestion of complex carbohydrates, but also on metabolic effects of colonic starch fermentation (Wachters-Hagedoorn et al 2007). Acarbose $\left(\right.$ Glucobay $\left.^{\circledR}\right)$ is the most widely prescribed AGI. The other AGIs are miglitol $\left(\right.$ Glyset $\left.^{\mathbb{}}\right)$ and voglibose $\left(\right.$ Volix $^{\circledR}$, Basen $\left.^{\circledR}\right)$. AGIs might be a reasonable option as first-line drug in the treatment of patients with DM2 as it specifically targets postprandial hyperglycemia, a possible independent risk factor for cardiovascular complications (Ceriello 2005). Although rare cases of hepatic injury were described, AGIs are expected to cause no hypoglycemic events or other life-threatening events, even at overdoses, and cause no weight gain (Chiasson et al 2003).

\section{Effectiveness of AGls in DM2: results of a Cochrane Review}

A Cochrane systematic literature review and meta-analysis investigated the effects of AGIs versus placebo (or any other intervention) with respect to mortality and (diabetes-related) morbidity, glycemic control, plasma lipids, insulin levels and body weight and side effects (Van de Laar et al 2005). In total, 41 studies were included ( 30 acarbose, 7 miglitol, 1 voglibose, 3 combinations). There was no evidence for an effect on mortality or morbidity. The other outcomes for acarbose and miglitol compared to placebo and sulphonylurea are listed in Table 2. Compared with placebo, AGIs had a beneficial effect on glycated hemoglobin $(\mathrm{GHb})$ (acarbose $-0.8 \%, 95 \%$ CI $0.6-0.9$; miglitol $-0.7 \%, 95 \%$ CI $0.4-0.9$ ), fasting and postload blood glucose and insulin levels. None of the AGIs had an effect on plasma lipids. Body mass index decreased by $0.2 \mathrm{~kg} / \mathrm{m}^{2}$ (95\% CI 0.1-0.3), compared to placebo, although a similar meta-analysis for body-weight did not reach statistical significance (decrease $0.13 \mathrm{~kg} ; 95 \% \mathrm{CI}-0.20$ to 0.46 ). When compared with sulfonylurea, AGIs showed inferior glycemic control, but more decrease of fasting and postload insulin levels. Side effects of AGIs treatment were predominantly gastro-intestinal. When the dose exceeded $50 \mathrm{mg}$ tid, the side effects increased, the blood post-load glucose levels showed more decrease, but the beneficial effect on GHb did not increase. Although this effect is probably due to lower compliance in the higher dosage ranges, the conclusion that there is no need for dosages higher than $50 \mathrm{mg}$ acarbose tid seems justified. Too few comparisons with metformin were available to make a fair judgment. The seven available studies for miglitol are suggestive for comparable effects to acarbose. For voglibose only one study was found.

\section{Place of AGls in current therapeutic strategies A comparison with the other oral blood glucose lowering drugs}

In 2006, the American Diabetes Association and European Association for the Study of Diabetes together published a 'consensus statement' on the management of hyperglycemia. For all patients, metformin in combination with a lifestyle 


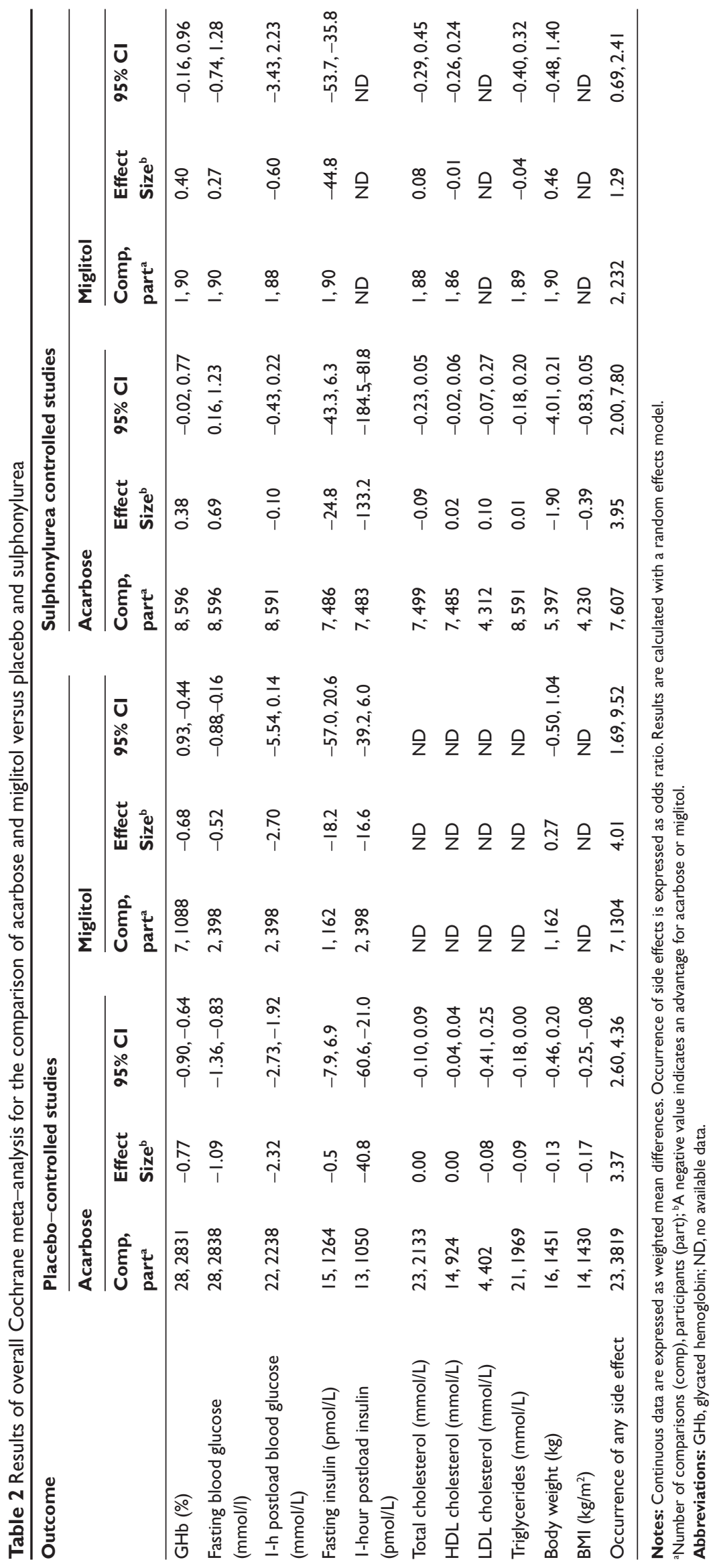


intervention is advised, followed by the addition of either a thiazolidinedione (TZD), a sulphonylurea, or insulin when $\mathrm{GHb}$ remains $\geq 7 \%$. AGIs are not included in the treatment algorithm, but is stated to be an "appropriate choice in selected patients" (Nathan et al 2006).

The guideline of the British National Institute for Clinical Excellence (2002) states that oral medication has to be initiated when lifestyle intervention alone fails. Metformin is therapy of first choice and sulphonylurea should be given in case of contra-indications for metformin, or should be added when therapy with metformin alone fails. TZDs are recommended to be added in case of contraindications for metformin, or if the combination of metformin and sulphonylurea fails. AGIs may be considered as an alternative glucose-lowering therapy in people unable to use other oral drugs (National Institute for Clinical Excellence 2002).

The guidelines of the Dutch College of General Practitioners (DCGP) have changed recently. Acarbose used to be recommended as a drug for the treatment of DM2 when sulphonylurea and/or metformin failed, or in case of contra-indications for one of these drugs (Rutten et al 1999). In the current Dutch guideline, however, the only AGI that is available in the Netherlands, acarbose, is no longer recommended (Rutten et al 2006). Instead, TZDs are introduced in the guideline to be used when metformin fails in obese patients (BMI $\geq 27 \mathrm{~kg} / \mathrm{m}^{2}$ ) with existing cardiovascular disease without an increased risk for heart failure. The low ranking of AGIs in all of these guidelines suggests that unequivocal evidence proving the superiority of the other oral drugs is available.

The case for metformin seems to be strong: metformin showed to reduce mortality and to have beneficial effects on diabetes-related morbidity compared to sulphonylurea or insulin (Anon 1998a). Moreover, in meta-analyses metformin compared to placebo showed to decrease HbAlc by $0.9 \%$ (Johansen 1999 ) or $1.0 \%$ (Saenz et al 2005). The cases for sulphonylurea and TZDs are less strong. The beneficial effects on microvascular complications that have been observed in patients using sulphonylurea or insulin, are most likely due to the effects of tight glycemic control and not due to direct effects of sulphonylurea (Anonymous 1998b). Moreover, no beneficial effects on diabetes related mortality and macrovascular morbidity has been found thus far for sulphonylurea. On the contrary, although the results of the University Group Diabetes Program suggesting an increased risk of cardiovascular morbidity with the use of tolbutamide were heavily criticized (Goldner et al 1971), sulphonylurea remained under the suspicion of unfavorable effects on cardiovascular disease up to now (Garratt et al 1999; Simpson et al 2006). In addition, sulphonylureas carry the risk of inducing life threatening hypoglycemic events.

TZDs are becoming more popular; this is reflected by the increased expenses of these drugs in the Netherlands: from 2 million Euros in 2001 to almost 24 million Euros in 2005 (Anon 2007). The PROACTIVE-study found a statistically significant effect for pioglitazone compared to placebo in addition to regular treatment in obese patients with DM2 and known cardiovascular morbidity on a secondary composite endpoint consisting of total mortality, non-fatal myocardial infarction and cerebrovasular accident resulting in a NNT of 50 patients (treatment duration 3 years) (Dormandy et al 2005). However, in a recent Cochrane systematic review with 22 trials on the efficacy of pioglitazone, it was concluded that thus far no convincing evidence for effects on mortality and morbidity exist and that the previously mentioned result of the PROACTIVE-study are hypotheses generating and need reconfirmation (Richter et al 2006). This precautious approach is underlined by results of a meta-analysis on another TZD, rosiglitazone, that showed an increased risk on myocardial infarctions and death from cardiovascular disease (Nissen and Wolski 2007). Moreover, it is important to realize that TZDs cause fluid retention and are therefore contra-indicated in patients with or at increased risk for heart failure.

Compared with the evidence for the currently recommended therapy (metformin, sulphonylurea, TZDs) as described above, the results of AGI-treatment, are less unfavorable than could be concluded from the low ranking of AGIs in the current guidelines. In indirect comparisons, the effect of AGIs on GHb is on average only $0.1 \%$ less compared to metformin (Saenz et al 2005) and 0.2 to $0.4 \%$ less compared to TZDs (Bolen et al 2007). Moreover, its effect on post-load glucose may be superior, although this is based on one comparison only (Hoffmann and Spengler 1997) and no data from meta-analyses are available. AGIs have a decreasing effect on the Body Mass Index, and the safety profile is favorable as there is no evidence for dangerous side effects. Most important, there are clues that AGI may prevent cardiovascular events in patients with impaired glucose tolerance in the STOP-NIDDM study (Chiasson et al 2003). However, this study is heavily debated and the results deserve re-confirmation (Chiasson et al 2004; Kaiser and Sawicki 2004). 'Evidence' from a study that reported beneficial effects of acarbose on myocardial infarctions in patients with DM2 has to be neglected because of publication bias, heterogeneity, detection bias and confounding (Hanefeld 2004; Van de Laar and Lucassen 2004). The results of three recently performed 
trials are underway with mortality and morbidity endpoints in patients with abnormal glucose tolerance (Holman 2006; Kim 2006) and early diabetes (Tamita 2006).

The gastro-intestinal side effects of AGIs are clinically relevant and may affect compliance. In this respect, it is of interest that the Cochrane review found evidence that acarbose in a low dose (50 mg tid) has similar effects on $\mathrm{GHb}$ and less side effects compared to the double dose (100 mg tid) (Van de Laar et al 2005). Other possible disadvantages are the relatively higher costs compared to sulphonylurea and the need for a 3-times daily dosage schedule as opposed to TZDs or sulphonylurea that may be taken once or twice daily.

Altogether, AGIs appear to be a serious therapeutic option in the treatment of DM2 as they have a comparable effect on glycemic control compared to metformin, they pose no risk for harmful adverse events, they decrease body mass index, they possibly reduce the risk for cardiovascular disease and the side-effects may be reduced by administering a lower dose without influencing its effect on glycemic control. AGIs are not necessarily a drug in the form of a pill as it may also be given as 'smart food' or as a food supplement. For example, a soy-bean derived touchi extract, a traditional Chinese food in the form of a paste, has shown to have alpha-glucosidase inhibiting properties and reduce blood glucose levels (Fujita et al 2001).

\section{AGIs in patients with impaired glucose tolerance or impaired fasting blood glucose}

Two risk factors for the development of DM2 (and cardiovascular disease) are impaired glucose tolerance (IGT) and impaired fasting blood glucose (IFBG). Both are generally recognized as an expression of abnormal glucose homeostasis that is not (yet) severe enough to meet the criteria for DM2. If one decides to treat these conditions, diet and exercise are an effective method to improve glucose tolerance and are recommended as first choice treatment (Nathan et al 2007). With life-style modifications, a relative-risk reduction (RRR) in the progression to DM2 of 58\% may be achieved (Tuomilehto et al 2001). Pharmacological treatment of IGT and IFBG may seem controversial, since it may implicate medicalization of the non-ill. According to a limited number of studies, especially drugs that improve insulin sensitivity may be useful in IGT and IFBG. Studies have been carried out with metformin (RRR of $31 \%$, endpoint DM2) (Knowler et al 2002), and rosiglitazone (RRR of $60 \%$, combined endpoint diabetes and death) (Gerstein et al 2006).

\section{Effectiveness of AGls in IGT or IFBG: results of a Cochrane Review}

A Cochrane systematic literature review assessed the effects of monotherapy with AGIs (acarbose, miglitol or voglibose) in subjects with IGT or IFBG with respect to the development of DM2, cardiovascular disease, glycemic control, serum lipid profile, blood pressure, body weight and side effects (Van de Laar et al 2006).

All randomized controlled trials of at least one-year duration, comparing AGI monotherapy with any other intervention were searched. In total, 5 trials were included (2360 participants). The results were dominated by one large scale study at low risk of bias (Chiasson et al 2002), the others were at high risk. Meta-analyses were not possible because of the limited data. Data from the first-mentioned study suggest that acarbose decreases the occurrence of DM2 (RR 0.78, 95\% CI 0.68-0.90, NNT $=10)$ and cardiovascular events (RR 0.46, $95 \%$ CI $0.26-0.86$, NNT $=50$, based on 47 events). However, the study was not initially powered for the latter outcome and this finding needs confirmation in more studies.

\section{Place of AGls in preventive strategies}

In the Cochrane review, it was found that acarbose reduces the incidence of DM2 in patients with IGT. However, it remains unclear whether this should be seen as prevention, delay or masking of diabetes. Also, a preventive effect on combined cardiovascular endpoints on the occurrence of cardiovascular events was found, but this finding needs to be confirmed because it was based on only 47 events in one study. Moreover, this study was not originally powered for that goal (Chiasson et al 2003). In the coming years, more data will be available from studies that have already been finished but yet unreported in full detail (Holman et al 2003; Nijpels 2005), and from studies that are currently ongoing (Kim 2006; Tamita 2006; Holman 2006). Thus far, lifestyle interventions are still much more effective in reducing the incidence of DM2 than AGIs (Knowler et al 2002; Ratner et al 2005; Tuomilehto et al 2001).

Nevertheless, regardless of available data, the question arises whether drug interventions in people with no disease and who do not even feel ill is desirable. General Practitioners are often confronted with the medical consequences of societal problems such as the massive adoption of sedentary lifestyles or loneliness and social isolation. But, just like a banker will talk money when confronted to problems, a doctor will most likely 'talk medicine' even when confronted with non-medical problems. This issue of medicalization, raised in the seventies of the twentieth century, is to date still actual and even more 
complicated than before (Gupta 2003; Metzl and Herzig 2007). In a focus group study with Welsh doctors and practice nurses unnecessary medicalization was a major concern with respect to preventive treatments for DM2 (Williams et al 2004). No one will have the solution to the problem were the border should be between the medical domain and the responsibility of society as a whole, governments, schools and, last but not least, the individual himself. But asking the question in this philosophical and ethical issue is probably more important than any possible answer.

\section{Acknowledgment}

I thank M.M.L. Stikkelbroeck, MD, PhD, for her helpful comments on the manuscript.

\section{Disclosures}

The author has no conflicts of interest to disclose.

\section{References}

Anonymous. 1998a. Effect of intensive blood-glucose control with metformin on complications in overweight patients with type 2 diabetes (UKPDS 34). UK Prospective Diabetes Study (UKPDS) Group. Lancet, 352:854-65.

Anonymous. 1998b. Intensive blood-glucose control with sulphonylureas or insulin compared with conventional treatment and risk of complications in patients with type 2 diabetes (UKPDS 33). UK Prospective Diabetes Study (UKPDS) Group. Lancet, 352:837-53.

Anonymous. 2007. Totale kosten 2001-2005 voor ATC-subgroep A10BG: Thiazolidinedionen. Raming voor Ziekenfondswet en particulier verzekerden [online]. Accessed 6 June. 2007 URL: http:// www.gipdatabank.nl.

ADA. 2007. Diagnosis and classification of diabetes mellitus. Diabetes Care, 30:S42-S7.

Baan CA, Poos MJJC. 2007. Neemt het aantal mensen met diabetes mellitus toe of af? [online]. Accessed 23 March 2007 URL: http://www.nationaalkompas.nl>Gezondheid en ziektelZiekten en aandoeningen $\backslash$ Endocriene, voedings-en stofwisselingsziekten en immuniteitsstoornissen $\backslash$ Diabetes mellitus.

Beaglehole R, Yach D. 2003. Globalisation and the prevention and control of non-communicable disease: the neglected chronic diseases of adults. Lancet, 362:903-8.

Bolen S, Wilson L, Vassy J, et al. Comparative effectiveness and safety of oral diabetes medications for adults with type 2 diabetes [online]. AHRQ Publication no. 07-EHC010-EF.2007.Accessed 31 July 2008 URL: http://effectivehealthcare.ahrq.gov/repFiles/OralFullReport.pdf

Campbell LK, White JR, Campbell RK. 1996. Acarbose: its role in the treatment of diabetes mellitus. Ann Pharmacother, 30:1255-62.

Ceriello A. 2005. Postprandial hyperglycemia and diabetes complications: is it time to treat? Diabetes, 54:1-7.

Chiasson JL, Josse RG, Gomis R, et al. 2002. Acarbose for prevention of type 2 diabetes mellitus: the STOP-NIDDM randomised trial. Lancet, 359:2072-7.

Chiasson JL, Josse RG, Gomis R, et al. 2003. Acarbose treatment and the risk of cardiovascular disease and hypertension in patients with impaired glucose tolerance: the STOP-NIDDM trial. JAMA, 290:486-94.

Chiasson JL, Josse RG, Gomis R, et al. 2004. Acarbose for the prevention of Type 2 diabetes, hypertension and cardiovascular disease in subjects with impaired glucose tolerance: facts and interpretations concerning the critical analysis of the STOP-NIDDM Trial data. Diabetologia, 47:969-75.
Dormandy JA, Charbonnel B, Eckland DJ, et al. 2005. Secondary prevention of macrovascular events in patients with type 2 diabetes in the PROactive Study (PROspective pioglitAzone Clinical Trial In macroVascular Events): a randomised controlled trial. Lancet, 366:1279-89.

Fujita H, Yamagamu T, Ahshima K. 2001. Long-term ingestion of a fermented soybean-derived Touchi-extract with alpha-glucosidase inhibitory activity is safe and effective in humans with borderline and mild type-2 diabetes. $J$ Nutr, 131:2105-8.

Garratt KN, Brady PA, Hassinger NL, et al. 1999. Sulfonylurea drugs increase early mortality in patients with diabetes mellitus after direct angioplasty for acute myocardial infarction. $J \mathrm{Am}$ Coll Cardiol, 33:119-24.

Gerstein HC, Yusuf S, Bosch J, et al. 2006. Effect of rosiglitazone on the frequency of diabetes in patients with impaired glucose tolerance or impaired fasting glucose: a randomised controlled trial. Lancet, 368:1096-105.

Goldner MG, Knatterud GL, Prout TE. 1971. Effects of hypoglycemic agents on vascular complications in patients with adult-onset diabetes. 3. Clinical implications of UGDP results. JAMA, 218:1400-10.

Gupta S. 2003. If everyone were on Prozac... Time, 161:81.

Hanefeld M. 2004. Meta-analysis of long-term studies to assess the effect of acarbose on cardiovascular risk reduction - scientifically credible: Reply. Eur Heart J, 25:1179-80.

Hoffmann J, Spengler M. 1997. Efficacy of 24-week monotherapy with acarbose, metformin, or placebo in dietary-treated NIDDM patients: the Essen-II Study. Am J Med, 103:483-90.

Holman RR. 2006. A new outcome trial with glucobay ${ }^{\circledR}$ - further investigation in diabetes and CVD prevention. Lecture at the symposium, titled 'Managing prediabetes - the global need for early intervention', at the Cape Town International Convention Centre, South Africa, December 3rd 2006 [online]. Accessed 27 July 2007 URL: http://www.diabetes-symposium.org/index.php?menu=view\& chart $=2 \&$ id $=346$

Holman RR, Blackwell L, Stratton IM, et al. 2003. Six-years results from the Early Diabetes Intervention Trial. Diabet Med, 20:15.

Johansen K. Efficacy of metformin in the treatment of NIDDM. Meta-analysis. Diabetes Care, 1999. 22:33-7.

Kaiser T, Sawicki PT. 2004. Acarbose for prevention of diabetes, hypertension and cardiovascular events? A critical analysis of the STOP-NIDDM data. Diabetologia, 47:575-80.

Kim J. 2006. Alpha-glucosidase-inhibitor blocks cardiac events in patients with myocardial infarction and IGT (ABC Study) [online]. Accessed 13 July 2007 URL: http://www.controlled-trials.com.

Knowler WC, Barrett-Connor E, Fowler SE, et al. 2002. Reduction in the incidence of type 2 diabetes with lifestyle intervention or metformin. N Engl J Med, 346:393-403.

Metzl JM, Herzig RM. 2007. Medicalisation in the 21st century: introduction. Lancet, 369:697-8.

Nathan DM. 2007. Finding new treatments for diabetes - how many, how fast... how good? N Engl J Med, 356:437-40.

Nathan DM, Buse JB, Davidson MB, et al. 2006. Management of hyperglycemia in type 2 diabetes: A consensus algorithm for the initiation and adjustment of therapy: a consensus statement from the American Diabetes Association and the European Association for the Study of Diabetes. Diabetes Care, 29:1963-72.

Nathan DM, Davidson MB, DeFronzo RA, et al. 2007. Impaired fasting glucose and impaired glucose tolerance: implications for care. Diabetes Care, 30:753-9.

National Institute for Clinical Excellence. 2002.Clinical Guideline G Management of type 2 diabetes, management of blood glucose. London, UK, National Institute of Clinical Excellence.

Nijpels G. 2005. Dutch Acarbose Intervention Trial (DAISI) [online]. Accessed 15 March 2006 URL: http://www.controlled-trials.com/ isrctn/trial///0/33274262.html

Nissen SE, Wolski K. 2007. Effect of rosiglitazone on the risk of myocardial infarction and death from cardiovascular causes. $N$ Engl $J$ Med, 356:2457-71. 
Ratner R, Goldberg R, Haffner S, et al. 2005. Impact of intensive lifestyle and metformin therapy on cardiovascular disease risk factors in the diabetes prevention program. Diabetes Care, 28:888-94.

Richter B, Bandeira-Echtler E, Bergerhoff K, et al. 2006. Pioglitazone for type 2 diabetes mellitus. Cochrane Database Syst Rev, CD006060.

Rutten GEHM, De Grauw WJC, Nijpels G, et al. 2006. Dutch College of General Practitioners: guidelines on Type 2 diabetes, second revision (in Dutch). Huisarts Wet, 49:137-52.

Rutten GEHM, Verhoeven S, Heine RJ, et al. 1999. NHG-Standaard diabetes mellitus type 2 (eerste herziening). Huisarts Wet, 42:67-84.

Saenz A, Fernandez-Esteban I, Mataix A, et al. 2005. Metformin monotherapy for type 2 diabetes mellitus. Cochrane Database Syst Rev, CD002966.

Simpson SH, Majumdar SR, Tsuyuki RT, et al. 2006. Dose-response relation between sulfonylurea drugs and mortality in type 2 diabetes mellitus: a population-based cohort study. CMAJ, 174:169-74.

Tamita K. 2006. Acarbose for secondary prevention of cardiovascular events in patients with coronary stenting and abnormal glucose tolerance [online]. Accessed 13 March 2006 URL: http://www. controlled-trials.com.

Tuomilehto J, Lindstrom J, Eriksson JG, et al. 2001. Prevention of type 2 diabetes mellitus by changes in lifestyle among subjects with impaired glucose tolerance. $N$ Engl J Med, 344:1343-50.
Van de Laar FA, Lucassen PL. 2004. No evidence for a reduction of myocardial infarctions by acarbose. Eur Heart J, 25:1179-80.

Van de Laar FA, Lucassen PLBJ, Akkermans RP, et al. 2006. Alpha-glucosidase inhibitors for people with impaired glucose tolerance or impaired fasting blood glucose. Cochrane Database Syst, Rev doi: 10.1002/14651858.CD005061.pub2.

Van de Laar FA, Lucassen PLBJ, Akkermans RP, et al. 2005. Alphaglucosidase inhibitors for type 2 diabetes mellitus. Cochrane Database Syst Rev, Art. No: CD003639. doi: 10.1002/14651858. CD003639.pub2.

Wachters-Hagedoorn RE, Priebe MG, Heimweg JA, et al. 2007. Low-dose acarbose does not delay digestion of starch but reduces its bioavailability. Diabet Med, 24:600-6.

WHO. 2006.Definition and diagnosis of diabetes mellitus and intermediate hyperglycaemia: report of a WHO/IDF consultation. Geneva, Switzerland, World Health Organization.

Williams R, Rapport F, Elwyn G, et al. 2004. The prevention of type 2 diabetes: general practitioner and practice nurse opinions. $\mathrm{Br} \mathrm{J} \mathrm{Gen}$ Pract, 54:531-5. 
